\title{
Leapfrog Technology and How It Applies to Trackless Tram
}

\author{
Vinnet Ndlovu, Peter Newman \\ Curtin University Sustainability Policy Institute (CUSP), Curtin University, Perth, Australia \\ Email: vinnet.ndlovu@postgrad.curtin.edu.au
}

How to cite this paper: Ndlovu, V. and Newman, P. (2020) Leapfrog Technology and How It Applies to Trackless Tram. Journal of Transportation Technologies, 10, 198-213.

https://doi.org/10.4236/jtts.2020.103013

Received: April 10, 2020

Accepted: May 15, 2020

Published: May 18, 2020

Copyright $\odot 2020$ by author(s) and Scientific Research Publishing Inc. This work is licensed under the Creative Commons Attribution International License (CC BY 4.0).

http://creativecommons.org/licenses/by/4.0/

\begin{abstract}
Rapid innovation and development of modern technology has brought about the opportunity for developing economies to technologically leapfrog. The smart phone is the most recent example. This paper assesses literature to show what technological leapfrogging is and the key criteria used to enable it to occur in developing countries. These include being "economical enough", "less technical", "lends itself to partnership", "lends itself to community engagement", "enables co-development" and "fulfills the sustainable development goals". The paper then examines the new mid-tier transit technology called Trackless Trams and applies the six criteria to it. The paper suggests that there are five good fits with the criteria and the sixth, the "less technical", can be accommodated in most developing cities through distributed solar energy systems and also smart technology systems through mobile phone-based communication infrastructure. The case for Trackless Trams to be part of the future in developing cities is therefore strong.
\end{abstract}

\section{Keywords}

Technological Leapfrogging, Trackless Trams, Socio-Technological Regime

\section{Introduction}

The surging urban explosion in emerging economies has overwhelmed their public infrastructure, which is already lagging in many aspects [1]. Addressing the problem would require concerted efforts from both the government and the private sector [2]. However, to skip the learning curve of the developed countries, there is an opportunity for emerging economies to explore the concept of technological leapfrogging by adopting emerging technologies [3]. This concept appears to be validated by the accomplishments that have been made in the telecommunication sector [4]. Telecommunication infrastructure is one of the critical 
networks necessary for promoting economic growth in developing nations. A cost-efficient and effective transport network is equally vital and necessary when it comes to promoting the desired economic development of these countries [5].

This study will explore the use of Trackless Tram Systems (TTS) as a potential leap-frog technology in rapidly growing cities of the global south. Given that most emerging economies, especially in Africa, are still in the process of exploring their options when it comes to building their various infrastructure networks, they are likely to benefit from technological leapfrogging [6]. The study addresses the questions:

- How can leapfrog technology be defined?

- What are the key requirements for enabling leapfrog technology?

- What is a Trackless Tram System?

- How does TTS apply to leapfrog technology requirements?

\section{How Can Leapfrog Technology be Defined?}

Technology leapfrogging is a relatively new area of study [7] though Schumacher (1974) tried to show in his concept of "intermediate technology" that the gigantism and high capital expense of much technology from the industrial west could be scaled down to fit emerging economies. It is possible that newer technologies in renewable energy and smart systems are already much more modular and easier to scale into affordable and appropriate forms for developing economies [8]. Nevertheless, technology leapfrogging will still need to fit into the development process seen today as necessary to achieve the kind of "inclusive, safe, resilient and sustainable cities" suggested through the United Nations' New Urban Agenda and SDGs.

According to Steinmueller [9], technological leapfrogging can be described as "bypassing stages in capability building or investment through which countries were previously required to pass during the process of economic development". The leapfrogging concept can take different forms, phases or stages [3]. Kimble and Wang [10] for instance, identified leapfrogging phases that can contribute to industrial growth when looking at transistors and electric vehicles. They identified three paths: the standard path, catching-up, and technological leapfrogging. The standard path is the usual pathways of technological development that were followed in the past. It is not considered as an "actual" leapfrogging path but the typical expected path of growth [11]. While the catching-up type is a fast-tracked leap that leads to economic and technical development through technological transfer interventions [9]. In this case, an "actual" leapfrogging does not occur. Instead, there is a technology transfer that necessitates the need to follow all stages of development but at an accelerated rate [12]. However, the actual technological leapfrogging assumes that bypassing certain stages of development is necessary if its benefits are to be felt rapidly [11].

Kimble and Wang [10] also identify three forms of technology leapfrog. They include stages of "skipping leapfrog", "path creating leapfrog", and "paradigm-changing leapfrog". Within the stage of "skipping leapfrog", one or more 
stages in the growth of the technology are omitted as demonstrated on Figure 1 that illustrates stages A, B and D with a skip of stage C.

"Path creating leapfrog", on the contrary, involves creating an alternate route for one or more stages instead of skipping a phase while adopting the technology [13]. Such a scenario is commonly seen in sectors where technological progress or improvements are continuously shifting, for instance, in the ICT software industry [10]. In contrast, paradigm-changing leapfrog occurs when the skipping uses new advanced expertise not available in the present socio-technological regime [10].

Based on the needs of the emerging economies, the paradigm-changing leapfrog stage appears to be the best form of leapfrogging that developing countries can attain, especially if it enables a new way of bringing in finance for development. However, the accomplishment of this phase does not automatically imply the redevelopment of the know-how itself. Instead, it could involve the implementation and use of expertise in a way that enables other matching technological capabilities. This happens through the ability to have smooth downstream integration capacities especially through communication systems [14] [15]. James [4] explains how the leap from fixed-line to mobile phone occurred and suggests ratio-focused approach that uses the idea and the effect of leapfrogging using mobile phones in developing economies.

Africa is recognized as the most prominent case of how the adoption of mobile phones eliminated the need to create resource-intensive fixed-line phone substructures [16]. However, a thorough assessment of the infiltration of the mobile phone in Africa showed that the region still lags [3]. Nonetheless, a comparative study of the proportion of mobile phones to fixed-line set-ups demonstrated that Africa was able to leapfrog by adopting mobile phones as their means of communication [16]. Another notable example of technological leapfrogging is when Papua New Guinea transitioned from traditional landline telecommunications systems to satellite-based communications in one leap [17]. Azerbaijan, a developing country in Asia, is also known to have reached a higher level of ICT connectivity in a short space of time [18]. In a bid to explain the transition taken by Azerbaijan to technologically leapfrog through its ICT system, Tan, Ng and Jiang [7] came up with the "Four Ps Framework Model". The model helps to explain the phases executed by the Azerbaijan government to pass its industrial leapfrogging within its ICT sector fruitfully. Below is the "Four Ps Framework Model" of technological leapfrogging developed by Tan, Ng and Jiang [7]:

- Stage 1: Psyching;

- Stage 2: Planting;

- Stage 3: Propelling;

- Stage 4: Perpetuating.

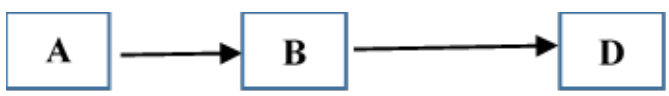

Figure 1. Stage skipping leapfrog [10]. 
According Tan, Ng and Jiang [7] stage 1 involved mostly building publicity around the project and designing the plan. While in stage 2, the project stakeholders established the resources that need to be used to make the project a success. This stage entailed understanding the existing capabilities. During the process, decisions on whether to procure new resources or adopt the "bricolage" strategy were made [18]. Bricolage can be less expensive and usually the only alternative for countries that have few resources. According to Tan, Ng and Jiang [7], the real ICT Development was implemented during stage 3. In other words, stage 3 mainly entailed launching the project through the development of the ICT infrastructure. Finally, during the perpetuating stage, there was an emphasis on maintaining the path of ICT development [18]. For Azerbaijan's ICT development project, the buy-in attitude and commitment to supporting the plan were influenced by the sharing of the quick wins and benefits among the stakeholders. Also, it is essential to understand that technological leapfrogging in Azerbaijan, mainly the ICT Development project was directed by sound and policy-driven tactics, which were endorsed by the ruling government [18]. As such, it was handled as a national scheme and supported by several governmental departments and the vision was well articulated and made public for all stakeholders to understand [18].

\section{What are the Key Requirements for Enabling Leapfrog Technology?}

Six requirements or criteria have been garnered from the literature on leap-frogging.

\subsection{Cost Effective: "Being Economical Enough"}

To get leapfrogging projects off the ground, capital investment is required. However, it is evident that inadequate financial resources, more so in developing countries, is a problem that could hinder any plan despite how ambitious it is [19]. Furthermore, even though aid could help in eliminating the challenge, there is a consensus that relying on aid agencies too much could be risky. According to the secretary general of the International Telecommunication Union (ITU), aid agencies can only be helpful if they act as intermediaries that bring together private sector players, network operators, and governments (ITU). The private sector can provide the needed capital for such projects [20]. This is not usually the case with transport projects that are more often than not left to governments to find the financial capital. Hence any technological leapfrog that can attract private capital to help with the upfront costs will be an important help.

\subsection{Capability and Capacity: "Being Less Technical"}

Leapfrogging is an appealing concept for developing countries. However, studies reveal that one of the main hindrances to implementing the concept is the lack of capability to produce such technologies in these emerging economies [21]. The developed countries contribute to the development of most of these technol- 
ogies [3]. The challenge is that developing countries have to procure these technologies from advanced nations through arrangements that may prohibit them from developing the ability to produce the technology and hence may have issues with its management [22]. The leapfrog concept is thus best sustained if a country possesses the expertise to help manufacture and be able to manage the related technology [21]. Gallagher [23] alludes that "there is a danger that selecting technology on or very near the frontier" can be damaging. This is reiterated by Dahlman, Ross-Larson [24] by saying "In order to leapfrog, you have to be a frog, not a tadpole". However, if a technology can build on other capacities which can be enabled through some training as it is "less technical", then that would be the kind of characteristic that lends itself to technological leapfrogging.

\subsection{Public Private Partnerships: "Lends Itself to Partnership"}

In other words, leapfrogging technology is not just a motivating conceptual occurrence, as it only works if it is executed as part of a more critical strategy, which is designed and reinforced by various policymakers [15]. To increase the chances of getting adopted, the technology should be viable enough to encourage partnerships and attract private investors who seek a stable return on their investment. The public-private partnership concept increases the likelihood of getting projects implemented quicker and efficiently [25].

\subsection{Transparency: "Lends Itself to Community Engagement"}

Lack of stakeholder engagement is also considered a challenge to leapfrogging technology. In most cases, the success of specific leapfrogging projects has been attributed to the ability to have all stakeholders on board [3]. For instance, the importance of including the stakeholders at the start of the initiative is also evidently demonstrated in the Azerbaijan ICT Development technological leapfrog project. The initiative had a vibrant vision and implementation plan. According to Tan, $\mathrm{Ng}$ [7], it was a continuous event that needed resources, including numerous stakeholders' input, to sustain its momentum.

\subsection{Broad Economic Development: "Enables Co-Development"}

Co-development is where social and cultural considerations are built into the economic development process. Cargo cult mindset is another leapfrogging challenge that needs to be addressed. Cargo cult mentality is the belief that the gains observed from the utilization of a know-how or technology by developed countries will be realized by simply adopting the same know-how or technology in a given different context or domain. It is vital to look at the context as it might not be the same with where the technology was used successfully. In some cases, the social context of technology has been under-emphasized, despite being crucial in making the adoption successful. In most cases, it is the social setting that determines the recognition and successful implementation of the technology. As such, it highlights the importance of planning and policies in increasing the like- 
lihood of success. Azerbaijan and its ICT Development project stand out as an ideal example in this case. Planning and conducting an assessment of a fitting technology by taking into account the cultural and socio-economic settings and universal standard for interoperability is critical in avoiding costly errors and failure [17].

\subsection{Wider Outcomes: "Fulfils Sustainable Development Goals"}

Leapfrogging technology will not ultimately work in any society unless it is part of a set of wider outcomes [26]. These have been outlined by the UN and adopted by 193 countries as the SDGs [27]. Therefore, government policy that assesses leapfrog projects in terms of the SDG's, is essential for enhancing the ability to facilitate and support technological leapfrogging [21].

\section{What is A Trackless Trams System (TTS)}

According to Newman et al. [28] TTS can be categorized as a mid-tier transit system equivalent to a light rail. The main difference is that TTS run on rubber tyres and has batteries on the roof; this means no steel tracks and no overhead wires and hence it is likely to be much cheaper and quicker to implement. The TTS therefore appears to be a likely candidate to be a leapfrog technology. The paper will therefore move to examining this potential.

Physical Attributes of Trackless Trams. Trackless trams use an electric drive system that is power-driven by battery technology [28]. Such an attribute eliminates the need to use overhead electrical cables and as its electric it can use renewable electricity rather than using non-renewable fuel [29]. Using rubber tyres instead of steel rails is also another feature of trackless trams technology that makes it have an advantage over light rail [28]. For instance, the rubber tyres eliminate the massive cost and the disruption associated with building steel rails through built-up cities and busy streets. Furthermore, trackless trams possess the same ability obtainable by high speed rail, which offers stabilization technologies through train-type bogeys with low set axles and hydraulic systems intended to avoid sways and bounce [28]. Lastly, trackless trams utilize up-to-date self-directed driverless technology using the ultra-modern optical guidance system that enables the tram to offer smoother trips and accurate docking at various locations, though the TTS always uses a driver to oversee its safety in mixed traffic [28].

Trackless trams can use dedicated passages to improve its performance through more rapid transit and better use of its self-directed driverless technology [30]. This can provide a high capacity service like a quality rail service. Having this capability gives TT an advantage when it comes to future city planning because it means they have the potential to be used for city redevelopment purposes. Fixed stations will be constructed within the dedicated corridors and can be a key way to enable partnership funding to be attracted to enable financing. A control center can be built that enables the service to be monitored and to suggest variations to the trams if there are problems that need to be avoided. This 
can be done easily as the autonomous system can be overridden to enable the driver to operate the trams manually. This ability means that they could be driven around obstructions or obstacles in a scenario where it needs to pass through construction and accident sites. Table 1 summarizes the main physical design of a three-car carriage trackless tram.

Table 1. Vehicle Specifications for a 3-Module Trackless Tram. Note: these are the characteristics of the CRRC Trackless Tram. Other TTS are being built in Europe.

\begin{tabular}{cc}
\hline Physical Attribute & Metric \\
\hline Length & $31.6 \mathrm{~m}$ \\
Wight & $2.65 \mathrm{~m}$ \\
Weight (loaded) & 51 tonnes (average 9 tonnes per axle) \\
Capacity & $250-300$ people \\
Max speed & $70 \mathrm{~km} / \mathrm{hr}$ \\
Gradient & $13 \%$ \\
Turning Radius & $15 \mathrm{~m}$ \\
Design Life & Over 30 years \\
Power supply & Rechargeable electric batteries \\
Operation & Automatic/manual \\
Car body construction & Space frame with bolted-on panels \\
Wheels driven & Rubber wheel \\
Bogies & Multi-axle steering system
\end{tabular}

Source: [28].

The other key features are outlined below emphasizing their potential to make TTS a leapfrog technology.

\subsection{Rubber Tyres}

The most significant task associated with adopting a light rail system is the need to construct the steel rails in a way that generally means underground services in the road need to be moved [28]. This requirement is primarily considered a challenge because it is costly and disruptive to the environment, the local economy and the local community. On the contrary, a trackless tram runs on rubber wheels on the road, a feature that offers an opportunity to circumvent disruptive and capital-intensive construction works associated with building steel rail substructure required by the light rail trains [28].

This is one of the main reason cities in China and Europe are moving to a mid-tier transit system that does not disrupt their cities' economies. The potential is to deliver a TTS in a weekend (after some road preparations) instead of several years of building tracks in busy road systems. They can also be part of the city's activities in the road system instead of having to tunnel or to put the transit above the traffic-filled streets on gantries and overpasses which are all very 
expensive and are not easy to integrate into land uses.

The rubber tyre systems are similar to buses in terms of their potential damage to roads and long-term tests may show more significant road-beds with greater concrete in them but tests so far are not indicating much damage.

\subsection{Self-Guiding}

The latest guided routing technology utilized by trackless trams is also a feature that makes the technology better than most on-road buses and cars. In particular, the technology enables TT to pass along "virtual rails", an ability that is also aided by up-to-date satellite navigation technology and the differential global positioning system (DGPS) [28]. At the same time, there is also a detection system that boosts the vehicle capability to distinguish road signs, and any intrusion that may be encountered. Finally, to aid the self-guidance ability, lines are marked on the road to offer optical control needed for virtual rails and enhance other road users' visibility [28]. These technologies are rapidly being adopted in cities across the world however as will be explained below it is also possible to simply use mobile phone technology to enable the basic operations of the TTS along with a driver that can over-ride the system whenever needed.

\subsection{Electrification and Energy Storage}

The vehicles utilize electric energy that is powered by lithium-ion phosphate batteries. The batteries used to power the TT can be recharged at a $10 \mathrm{kV}$ platform-style overhead charging station during regular operation [28]. The 600 $\mathrm{kW}$-Hr onboard batteries recharge faster compared to most cells. However, recharging can be done at the depot overnight. Battery technology is rapidly improving the range of vehicle distance so TT systems have moved from a range of approximately 15 to $25 \mathrm{~km}$ using a 10-minute charge and are considered likely to reach 50 to $60 \mathrm{~km}$ within a few years [28].

The highly projected move away from the consumption of fossil fuels makes the incorporation of Trackless Trams into road-based transit a suitable choice since it can utilize renewable energy and indeed this can be provided as roof-top solar panels at stations and depots. Storage can be supplemented for evening recharge by using batteries at stations and depots. The electrical drive system offers a smooth trip, which surpasses the ride-experience attained from fuel-based combustion engine automobiles and buses and is a major attraction for urban developers in building around stations.

Because of the potential to build a partnership-based TTS with private developers it is also possible to make a whole corridor of solar-based buildings integrated with electric transit as a demonstration of a new economy zero-carbon urban development. Such an option could be financed through Climate Funds. Depending on its location such a corridor could also include electric micromobility for last mile/first mile integration, especially with electric autorickshaws in developing cities. 


\subsection{Cost Efficiency}

The budget associated with building a light rail system is relatively higher in comparison to the investment in a TTS [31]. Specifically, a survey conducted by Bodhi Alliance and EDAB in 2017 reveals that constructing a Trackless Tram will be threefold cheaper as opposed to adopting a light rail system [31]. The significant differences in capital costs are associated with the fact that light rails are usually erected in high-density areas that have buried pipes and wires, which complicate the entire construction process [28]. As such, the cables and pipes have to be dug up and relocated, increasing the associated costs. Such complications and high costs were witnessed in the building of The Sydney Light rail. It is estimated that the system costed approximately 130 million US dollars per $\mathrm{km}$, a figure that is tenfold more than the expenditure on a TTS [28].

\subsection{Interoperability}

Trackless trams can be interconnected with heavy point mass rapid transportation stations considering their capacity to be utilized for the "first and last-mile service" [31]. For instance, trackless trams can be linked to central bus depots or inter-city rail stations [28]. In essence, the TTS is a mid-tier connector that can make a city function more effectively. It would mean that the trackless trams could transport passengers from central business districts (CBD) to the inner parts of the city as well as to major destinations in the suburbs, thereby decreasing the number of small vehicles or buses flooding congested central areas [31]. Similarly, the trackless trams can ferry passengers from the CBD to major rail stations or bus stations that take people out of the city.

Considering all the factors discussed above, it is seemingly apparent that this advanced technology has the ability and potential to offer the highest quality ride that one can experience from the light rail and bus rapid transit systems. The trackless trams can provide smooth rides and versatility, which is similar to what is experienced in light rail vehicles and buses, respectively. Furthermore, the cost associated with adopting the trackless trams is considerably lower, making it an attractive option.

\section{How does TT Apply to Leapfrog Technology Requirements?}

\subsection{Cost Effective: "Being Economical Enough"}

As described above the TTS is perhaps a tenth of the cost of a light rail system. Because it can be part of a solar-electric system its operational costs are also significantly less than a bus system. The transition to an electric grid that is zero carbon requires a lot more systems that can balance the grid and the role of batteries in this is growing rapidly. Electric bus systems are increasing rapidly and finding that grid services can help pay for the costs of building such systems through using bus batteries at depots as part of grid services. This is an important consideration in using TTS as a first step in this transition. Climate funds are an obvious source for leapfrogging with a TTS. 


\subsection{Capability and Capacity: "Being Less Technical"}

"Capability and capacity" implies that for leapfrogging to be accomplished, the technology must possess the following capabilities:

- Develop an absorptive capacity to create or utilize the expertise: concerning this requirement, Steinmueller [9] deliberates on the importance of the necessity to be capable of building the ability to come up with the same know-how in the local market and adopt the technology economically. Doing so will ensure that the technology can be easily domesticated to suit the needs of the locals. This can be done and the TTS can be fully built in any developing area. The TTS is also able to build on the technology and work practices of bus services thus using local know-how.

- Ease of access and ability to make productive use of the technology: such a prerequisite emphasizes the ability to obtain the technology as well as use it effectively to facilitate development [9]. The TTS is a promoter for desired economic growth and the restoration of cities' corridors as further outlined below.

- The technology should have corresponding technical abilities: this requirement examines the complementary strength of the technology to enable it to work with matching but not necessarily the same know-how [5]. Trackless trams can lead other sectors to raise their standard. Introducing the TTS would mean that the roads must also be kept to a high standard. Mobile phone systems can be used to help manage the TTS and enable leapfrogging benefits to both the transit system and the mobile phone services. Ticketing systems and stations used by the trackless trams can also be utilized by buses and other vehicles as the technology has the ability to stimulate co-development projects such as battery recharging stations. TT stations could be made with amenities that can permit public recharging of other electric vehicles such as electric-tuktuks, scooters and bikes as well as motor vehicles. This can make the transition away from oil to be even more rapid with multiple advantages.

- Realizing downstream incorporation capabilities: this precondition highlights a vital need to create some degree of assimilation with other sectors downstream or upstream [9]. The technology being used in Trackless Trams has a higher likelihood of downstream connectivity through ITC systems like ticketing and observation of the services for management purposes. The technology can exchange and use data cohesively, an aspect that can enable it to be utilized as the primary and the last mile service for ticketing as well as for data management in the system.

TTS can thus offer a rapid transit service that is similar to that provided by the popular light rail systems being built in developed cities, and thus is offering a leapfrog technology that jumps from jitney style on-demand systems that cram into the streets of many developing cities unable to create a good bus service and where mass transit is way out of their financial and technical grasp. It leapfrogs into a mid-tier mass transit system. 


\subsection{Public Private Partnerships: "Lends Itself to Partnership"}

The partnerships needed for a TTS include: Land development with the private sector around station precincts to make the most out of the obvious TOD advantages that are created through increased land values; and Electric micromobility services such as e-tuktuks, e-scooters and e-bikes which can be provided by private operators of these systems and which can feed into each of the stations. Such partnership potential is inherent to the technology and should translate easily to any part of the developed or developing world.

\subsection{Transparency: "Lends Itself to Community Engagement"}

Community engagement is likely to happen without much need for forced interventions as most communities are very involved in local transport issues. The key to a successful TTS that leapfrogs into a developing city, is that it must be inclusive of all people in the corridor including street businesses and small enterprises that are easily forgotten in such redevelopments. The need to conserve and create a range of housing options is also critical to the equity considerations of such transit systems.

\subsection{Broad Economic Development: "Enables Co-Development"}

If strategically adopted, TTS have the potential to restructure the city and boost the revival of urban areas along identified passages in a co-development process with multiple economic development outcomes. The following benefits could be realized if trackless trams are implemented.

\subsubsection{Sprawl Relief}

High urban density levels are associated with many benefits, such as economic growth [32]. Strategic and practical adoption of trackless trams along transit corridors will increase urban density on those passages, consequently minimizing the impending urban sprawling [28] [33].

\subsubsection{Congestion Relief}

Traffic congestion is one of the leading urban problems experienced both in developing and developed countries [34]. Traffic congestion was estimated to cost the US roughly $\$ 121$ billion in 2012 [28]. The figure is equivalent to $\$ 818$ per commuter every year [28]. Moreover, according to Newman et al. [28], an additional 25 million tonnes of greenhouse gases are emitted annually due to urban development that is car dependent rather than transit-based. Strategic and practical adoption of trackless trams can considerably minimize the number of vehicles in a city, thereby reducing the emission of harmful gases.

\subsubsection{Reclaim Car Parking}

Most cities, more so those that are highly dependent on the automobile, have allocated vast portions of land to car parks. According to Newman et al. [28], urban areas that are dependent on vehicles around the globe usually allocate between 5 and 8 parking spaces for every single vehicle in the city. These pieces of 
land can be redeveloped for productive and profitable use. There is no doubt that trackless trams can be a valuable addition to the reclaimed sites. Trackless trams can be integrated into the redevelopment programs to create value through Transit-Oriented Development schemes [28].

\subsubsection{Job Creation}

Studies reveal that a high level of urban density is positively associated with an improved level of the knowledge-based economic activity, which is the fastest growing part of most economies [28]. Companies tend to agglomerate around denser parts of urban areas. For instance, studies have revealed that an increase in a country's level of density index was associated with the improvement of state-level productivity [28] [35]. A TTS can help enable these dense centers to work effectively without heavy traffic.

\subsubsection{Health Benefits}

The most important health outcomes from a transport solution are associated with the level to which people walk less or more in their daily transport activity. Newman et al. [28] suggest that less car dependence can save as much in health costs as it costs to subsidize new suburbs with infrastructure. Furthermore, inhalation of vehicle fumes for long periods is associated with adverse health outcomes, especially from diesel fumes.

\subsection{Wider Outcomes: "Fulfils Sustainable Development Goals"}

As mentioned above, the technology associated with trackless trams will considerably reduce the emission of harmful gases with multiple health advantages [30]. Therefore, trackless trams should bring both social and environmental benefits. Adoption of trackless trams would lead to a decrease in cars on roads, thus minimizing the amount of $\mathrm{CO}_{2}$ emissions [28]. Furthermore, as the urban density increases, the proportion of energy use per person lessens, resulting in a smaller amount of $\mathrm{CO}_{2}$ emissions. Moreover, the adoption of trackless trams could potentially restore the corridors needing urban regeneration, consequently discouraging urban sprawl and saving agricultural land on the borders of the city [28].

As outlined above the TTS can attract development that creates jobs and hence enable social and economic development relevant to a number of the SDG's. The extent to which the city can create social advantages will depend on how well they do their community engagement and are inclusive of affordable social housing initiatives.

\subsection{Conclusions to Leapfrog Assessment Based on Six Criteria}

Trackless trams have the potential to aid emerging cities to technologically leapfrog while also contributing to the realization of SDGs and responding to the climate agenda. The low capital cost associated with trackless trams means that developing countries also have a chance to provide a modern infrastructure network that will increase their cities' ability to grow sustainably. As outlined by 
Newman et al. [28], the technology is viable enough to encourage partnerships and attract private investors who seek a stable return on their investment.

Table 2 below summarizes all the qualities and traits that make the TTS an ideal leapfrog technology.

Table 2. Summary of the TTS' leapfrog capabilities.

\begin{tabular}{|c|c|c|}
\hline $\begin{array}{l}\text { Leapfrog Technology } \\
\text { Requirements }\end{array}$ & $\begin{array}{c}\text { Application to } \\
\text { Trackless Tram } \\
\text { Systems }\end{array}$ & Comments \\
\hline 1. Economical enough & & $\begin{array}{l}\text { Very cheap mass transit, not as cheap as } \\
\text { separate buses or jitneys. See also } 3 \text {. }\end{array}$ \\
\hline 2. Less Technical & & $\begin{array}{l}\text { Requires some smart systems but only enough } \\
\text { for mobile phone telephony }\end{array}$ \\
\hline 3. Lends itself to Partnership & & $\begin{array}{l}\text { Ideal for working with developers who can help } \\
\text { finance it through urban centres at stations. }\end{array}$ \\
\hline $\begin{array}{l}\text { 4. Lends itself to Community } \\
\text { Engagement }\end{array}$ & & Communities are very keen for better transit. \\
\hline 5. Enables Co-development & & $\begin{array}{l}\text { Many overlaps with economic development as } \\
\text { it creates agglomeration economies. }\end{array}$ \\
\hline $\begin{array}{l}\text { 6. Fulfils Sustainable } \\
\text { Development Goals }\end{array}$ & & $\begin{array}{l}\text { Very strong on all SDG's due to equity, health } \\
\text { and environmental improvements. }\end{array}$ \\
\hline
\end{tabular}

\section{Conclusions}

There is an expectation that a successful technological leapfrog will facilitate the adoption of a progressive socio-technical regime that will lead to socio-economic development. This paper has examined the techno-physical and socio-economic attributes of the trackless trams technology to see if this expectation can be realized. Based on the analysis of physical features that make a technology to be considered to have the abilities to enable leapfrogging, the paper concludes that the trackless tram system certainly meets those requirements. One of the main looked-for attributes of a technology needed to augment leapfrogging discussed in the paper is the ease of implementation and deployment. TTS can be easily deployed and integrated into other systems within society. Acquiring and utilizing TTS for commercial purposes is less challenging. A TTS can considerably minimize the current problem of having numerous cars and small buses or jitneys on the road. At the same time, a TTS has the interoperability and matching technological proficiencies and utilization to build on the know-how of most developing cities. They can be a major mid-tier connector across cities linked by first and last mile service through small buses and jitneys and connect to major centers like the CBD as well as bus or train stations.

The paper has also examined the social and economic benefits associated with trackless trams. Cities in developing countries are struggling to build the infrastructure needed for driving economic growth and development. From the discussion above, TTS can help to mitigate this challenge and improve and create social and economic benefits. The technology can also help minimize urban sprawl and increase urban density levels. Studies have revealed that there is a 
correlation between population density index levels and the knowledge-based economy. For example, higher density index levels encourage the development of knowledge-economy jobs. At the same time, traffic congestion can significantly be reduced if TTS is effectively and strategically adopted. The paper has also deliberated on the possibility of financial gain should the vast parking land be reclaimed and be put into commercial use.

Leapfrogging technology has its challenges. Certain factors might make its implementation difficult. The paper has outlined some of the expected barriers to this idea. The impediments identified include lack of capability and capacity, government policy, cargo cult, and lack of stakeholder engagement and funding. The paper therefore concludes by suggesting that strategies and plans should be developed that support technological leapfrog initiatives. Azerbaijan is an ideal case of how government involvement is key to the success of such projects using ITC and the TTS is many ways could be seen as a similar kind of project as it will need to have a reasonable ITC system to support it.

Finally, a TTS will need to attract funding and financing and the paper has suggested that the TTS has considerable benefits in helping with this critical component of economic development. The TTS lends itself to a partnership with urban development along any proposed corridor. There is a need to promote a favorable environment that facilitates the adoption of such inventions to encourage investment from the private sector. The adoption of a TTS is mostly feasible if delivered using an entrepreneurial approach and includes the private sector and all stakeholders from the onset. Such partnerships are likely to create multiple benefits in co-design that can be realized once the trackless tram system is adopted. The paper suggests that the technology has most of the needed attributes to augment technological leapfrogging in transport.

\section{Conflicts of Interest}

The authors declare no conflicts of interest regarding the publication of this paper.

\section{References}

[1] Bitar, J., et al. (2016) Leapfrogging: Value-Based Health Care Comes to Emerging Markets.

https://www.bcg.com/en-au/publications/2016/health-care-payers-providers-leapfr ogging-value-based-health-care-comes-to-emerging-markets.aspx

[2] Tuangratananon, T., et al. (2019) China: Leapfrogging to Become a Leader in Global Health? Journal of Global Health, 9, Article ID: 010312. https://doi.org/10.7189/jogh.09.010312

[3] Fong, W. and Michelle, L. (2009) Technology Leapfrogging for Developing Countries. https://journalistsresource.org/wp-content/uploads/2013/04/Technology-Leapfrogg ing-for-Developing-Countries.pdf

[4] James, J. (2009) Leapfrogging in Mobile Telephony: A Measure for Comparing Country Performance. Technological Forecasting \& Social Change, 76, 991-998. https://doi.org/10.1016/j.techfore.2008.09.002

[5] McConnell, H. and Chathoth, P. (2008) Leapfrog Technologies for Health and Development. Technological Innovations, 5, 130-135. 
[6] Chakravorti, B. and R. Chaturvedi, Shankar. (2019) Research: How Technology Could Promote Growth in 6 African Countries. Harvard Business Review. https://hbr.org/2019/12/research-how-technology-could-promote-growth-in-6-afric an-countries

[7] Tan, B., Ng, E. and Jiang, J. (2018) The Process of Technology Leapfrogging: Case Analysis of the National ICT Infrastructure Development Journey of Azerbaijan. International Journal of Information Management, 38, 311-316. https://doi.org/10.1016/j.ijinfomgt.2017.10.008

[8] Newman, P., Beatley, T. and Boyer, H. (2012) Resilient Cities. Rizzoli, New York.

[9] Steinmueller, W.E. (2001) ICTs and the Possibilities for Leapfrogging by Developing Countries. International Labour Review, 140, 193-210. https://doi.org/10.1111/j.1564-913X.2001.tb00220.x

[10] Kimble, C. and Wang, H. (2012) Transistors, Electric Vehicles and Leapfrogging in China and Japan. Journal of Business Strategy, 33, 22-29. https://doi.org/10.1108/02756661211224979

[11] Hung, T.-Y., Hsiao, Y.-J. and Wu, S.-W. (2014) Advantage Management Strategy in Competition via Technological Race Perspective: Empirical Evidence from the Taiwanese Manufacturing Industry. The Scientific World Journal, 2014, 1-10. https://doi.org/10.1155/2014/843436

[12] DiSanzo, D. and Greenhill, R. (2014) Health Systems Leapfrogging in Emerging Economies.

http://www3.weforum.org/docs/WEF HealthSystem LeapfroggingEmergingEcono mies ProjectPaper 2014.pdf

[13] Lee, K. and Lim, C. (2001) Technological Regimes, Catching-up and Leapfrogging: Findings from the Korean Industries. Research Policy, 30, 459-483.

https://doi.org/10.1016/S0048-7333(00)00088-3

[14] Hashim, N.H., et al. (2014) Bandwagon and Leapfrog Effects in Internet Implementation. International Journal of Hospitality Management, 37, 91-98. https://doi.org/10.1016/j.ijhm.2013.10.012

[15] Ozcan, E. (2015) How Leapfrogging Can Help Developing Countries Surge Ahead. http://www.centreforpublicimpact.org/cleared-for-take-off/

[16] Koomson, W.K. (2018) Leapfrog Technologies: Can Mobile Technologies Competes Successfully with Traditional Learning Management Systems. Advances in Social Sciences Research Journal, 5, 157-164. https://doi.org/10.14738/assrj.58.5010

[17] Davison, R., et al. (2000) Technology Leapfrogging in Developing Countries: An Inevitable Luxury? Electronic Journal of Information Systems in Developing Countries, 1, 1-10. https://doi.org/10.1002/j.1681-4835.2000.tb00005.x

[18] Ng, E. and Tan, B. (2018) Achieving State-of-the-Art ICT Connectivity in Developing Countries: The Azerbaijan Model of Technology Leapfrogging. The Electronic Journal of Information Systems in Developing Countries, 84, e12027. https://doi.org/10.1002/isd2.12027

[19] Newman, P., Davies-Slate, S. and Jones, E. (2018) The Entrepreneur Rail Model: Funding Urban Rail through Majority Private Investment in Urban Regeneration. Research in Transportation Economics, 67, 19-28. https://doi.org/10.1016/j.retrec.2017.04.005

[20] International Telecommunication Union (ITU) (2020) Speeches by ITU Secretary-General, Dr Hamadoun I. Touré. https://www.itu.int/en/osg/Pages/speeches.aspx

[21] Winthrop, R. and McGivney, E. (2017) Can We Leapfrog? The Potential of Education Innovations to Rapidly Accelerate Progress. Skills for a Changing World, Brookings Institution, Center for Universal Education at the Brookings Institution. 
[22] Zuazua, M. and Schulz, O. (2018) How Businesses Can Win at Leapfrog. https://www.weforum.org/agenda/2018/01/how-businesses-can-win-at-leapfrog/

[23] Gallagher, K.S. (2006) Limits to Leapfrogging in Energy Technologies? Evidence from the Chinese Automobile Industry. Energy Policy, 34, 383-394. https://doi.org/10.1016/j.enpol.2004.06.005

[24] Dahlman, C.J., Ross-Larson, B. and Westphal, L.E. (1987) Managing Technological Development: Lessons from the Newly Industrializing Countries. World Development, 15, 759-775. https://doi.org/10.1016/0305-750X(87)90058-1

[25] Willoughby, C. (2013) How Much Can Public Private Partnership Really Do for Urban Transport in Developing Countries? Research in Transportation Economics, 40, 34-55. https://doi.org/10.1016/j.retrec.2012.06.038

[26] Conroy, M.M. and Berke, R.P. (2004) What Makes a Good Sustainable Development Plan? An Analysis of Factors That Influence Principles of Sustainable Development. Environment and Planning A, 36, 1381-1396. https://doi.org/10.1068/a367

[27] United Nations (2019) The Sustainable Development Goals Report 2019. United Nations, New York.

[28] Newman, P., et al. (2019) The Trackless Tram: Is It the Transit and City Shaping Catalyst We Have Been Waiting for? Journal of Transportation Technologies, 9, 31-55. https://doi.org/10.4236/jtts.2019.91003

[29] Hargroves, C., et al. (2018) Sustainable Urban Design Co-Benefits Role of EST in Reducing Air Pollution and Climate Change Mitigation.

https://apo.org.au/node/21521631 https://apo.org.au/sites/default/files/resource-files/2018-09/apo-nid215216.pdf

[30] Daley, M. (2018) Perth Needs to Ditch Cars and Embrace the "Second Rail Revolution". https://www.thefifthestate.com.au/urbanism/infrastructure/perth-second-rail-revol ution/

[31] Fleming, B. and McCabe, G. (2019) Are We on Track for Trackless Trams? http://urbis.com.au/insights-news/are-we-on-track-for-trackless-trams/

[32] Hendrigan, C. and Newman, P. (2017) Dense, Mixed-Use, Walkable Urban Precinct to Support Sustainable Transport or Vice Versa? A Model for Consideration from Perth, Western Australia. International Journal of Sustainable Transportation: Low Carbon Mobility, 11, 11-19. https://doi.org/10.1080/15568318.2015.1106225

[33] Dougherty, S. (2020) Trackless Trams Proposed for Perth to Get Passengers to Scarborough Beach from Glendalough Station, in PerthNow.

https://www.perthnow.com.au/news/perth/trackless-trams-proposed-for-perth-to-g et-passengers-to-scarborough-beach-from-glendalough-station-ng-b881487149z

[34] Gao, Y. and Newman, P. (2018) Beijing's Peak Car Transition: Hope for Emerging Cities in the 1.5 C Agenda. Urban Planning, 3, 82-92.

https://doi.org/10.17645/up.v3i2.1246

[35] Haughwout, A.F. (2000) The Paradox of Infrastructure Investment: Can a Productive Good Reduce Productivity? The Brookings Review, 18, 40-43.

https://doi.org/10.2307/20080926 